\title{
Consumo, digestibilidade aparente dos nutrientes e comportamento ingestivo de bovinos da raça Holandesa alimentados com dietas contendo feno de capim-tifton 85 com diversos tamanhos de partícula
}

\section{Elzânia Sales Pereira ${ }^{1}$, Ivone Yurika Mizubuti ${ }^{2}$, Edson Luis de Azambuja Ribeiro², Arturo Bernardo Selaive Villarroel ${ }^{1}$, Patrícia Guimarães Pimentel ${ }^{3}$}

\author{
${ }^{1}$ Departamento de Zootecnia - UFC - CE \\ 2 Departamento de Zootecnia - UEL - PR. \\ 3 Programa DCR - CNPq/FUNCAP. Departamento de Zootecnia - UFC - CE.
}

RESUMO - Avaliaram-se o consumo, a digestibilidade aparente de nutrientes da dieta e o comportamento ingestivo de novilhos recebendo dietas contendo feno de capim-tifton 85 com diferentes tamanhos de partícula (5, 7, $10 \mathrm{~mm}$ e inteiro). Utilizaram-se quatro novilhos da raça Holandesa, castrados, com peso vivo médio de $300 \mathrm{~kg}$ e idade média de $20 \mathrm{meses,} \mathrm{em}$ delineamento quadrado latino $4 \times 4$, com quatro animais e quatro períodos. Os consumos de matéria seca, matéria orgânica, proteína bruta, extrato etéreo, fibra em detergente neutro, fibra em detergente ácido, carboidratos totais e carboidratos nãofibrosos não foram influenciados pelos perfis granulométricos das dietas experimentais. Os coeficientes de digestibilidade da matéria seca diferiram significativamente entre as dietas com feno com partículas de 7 e $10 \mathrm{~mm}(67,31$ e $54,95 \%$, respectivamente). No entanto, os resultados obtidos com essas dietas foram semelhantes aos encontrados com partículas de $5 \mathrm{~mm}$ e com feno inteiro, cujos valores foram intermediários, com média de $63,62 \%$. O tempo de alimentação dos animais não diferiu entre as dietas com feno em artículas de 7 e $10 \mathrm{~mm}$ e inteiro. O tamanho de partícula do feno de capim-tifton 85 não influenciou o consumo, a digestibilidade dos nutrientes e o comportamento ingestivo de novilhos da raça Holandesa alimentados com dietas completas.

Palavras-chave: fibra efetiva, perfil granulométrico, ruminação, ruminantes

\section{Intake, apparent digestibility and ingestion behavior in Holstein steers fed diets containing Tifton 85 hay with different particle sizes}

\begin{abstract}
The intake, the apparent digestibility of nutrients and the ingestion behavior of four Holstein steers with average weight of $300 \mathrm{~kg}$ and 20 months of age, receiving diets containing Tifton 85 hay with different particle sizes $(5,7,10 \mathrm{~mm}$ and whole) were evaluated. A $4 \times 4$ Latin square experimental design with four steers and four periods was used. Intakes of dry matter, organic matter, crude protein, ether extract, neutral detergent fiber, acid detergent fiber, total carbohydrates and non-structural carbohydrates were not influenced by the different granulometric profiles of the experimental diets. The DM digestibility were different between diets with particles size of 7 and $10 \mathrm{~mm}(67.31$ and $54.95 \%$, respectively). However, these diets were similar to that with $5 \mathrm{~mm}$ of particle size and whole hay, which showed intermediate values, with mean of $63.62 \%$. The total feeding time of the animals that received diets with particles size of $7,10 \mathrm{~mm}$ and whole did not differ. The Tifton 85 hay with different particles size did notaffect the intake, digestibility of nutrients and the ingestion behavior of Holstein steers fed total mixed ration.
\end{abstract}

Key Words: effective fiber, granulometric profile, rumination, ruminants

\section{Introdução}

A probabilidade de o alimento ser ingeridopelo animal depende da ação de fatores que interagem em diferentes situações de alimentação, comportamento animal e meio ambiente. O consumo voluntário é a quantidade de alimento que um animal ingere durante determinado período, durante o qual tem livre acesso ao alimento (Forbes, 1996). Esse consumo é regulado por três mecanismos: o psicogênico, que envolve a resposta do animal a fatores inibidores ou estimuladores relacionados ao alimento ou ao ambiente; o fisiológico, em que a regulação é fornecida pelo balanço nutricional; e o físico, relacionado à capacidade de distensão do rúmen (Mertens, 1992). Por conseguinte, 
tamanho e condição corporal, raça e status fisiológicos são características inerentes aos animais e influenciam o consumo, pois alteram os requerimentos nutricionais, além da referida capacidade de distensão ruminal (Van Soest, 1994). Quando um ou mais metabólitos aparecem em excesso na corrente sanguínea em taxa superior à de sua remoção, resultando em maior concentração sanguínea, o sinal de saciedade é ativado, influenciando a ingestão de alimentos (Silva, 2006).

O consumo de forragem e outros alimentos fibrosos podem ser aumentados substancialmente por moagem e peletização. A redução do tamanho de partícula e a ruptura da estrutura da parede celular aumentam a densidade do alimento. Ocorre também a redução do tempo de ruminação, com concomitante aumento do tempo disponível para alimentação. A maior densidade permite taxa de digestão mais rápida, e menor volume ruminal. $\mathrm{O}$ aumento do consumo após a peletização foi verificado para forragens, com alto teor de fibras, de boa digestibilidade (Mertens, 1994). De acordo com Yang \& Beauchemin (2006), o tempo de ruminação e o tempo total de mastigação aumentaram linearmente com o incremento da FDN fisicamente efetiva em dietas para vacas leiteiras alimentadas com silagem de cevada com partículas de $9,5 \mathrm{~mm} ; 4,8 \mathrm{~mm}$ ou metade das partículas com 9,5 mm e metade das partículas com 4,8 $\mathrm{mm}$.

Este estudo foi realizado para avaliar o efeito de diversos tamanhos de partícula sobre o consumo, a digestibilidade aparente dos nutrientes e o comportamento ingestivo de animais da raça Holandesa alimentados com rações à base de feno de capim-tifton 85 com partículas de 5, 7, $10 \mathrm{~mm}$ e feno inteiro.

\section{Material e Métodos}

Este experimento foi realizado na Fazenda Antônio Carlos dos Santos Pessoa da Universidade do Oeste do Paraná - Unioeste, localizada no Campus de Marechal Cândido Rondon, Paraná. Foram utilizados quatro animais da raça Holandesa, pesando em média $300 \mathrm{~kg}$ de PV, fistulados no rúmen, alojados em baias individuais dotadas de comedouros convencionais e bebedouros adaptados. Os animais foram distribuídos em quatro dietas experimentais à base de feno de capim-tifton 85 (Cynodon dactylon) com diferentes tamanhos de partícula $(5,7,10$ $\mathrm{mm}$, inteiro) em delineamento experimental quadrado latino $4 \times 4$, composto de quatroanimais e quatro períodos. Cada um dos quatro períodos experimentais teve duração de 16 dias: 10 dias de adaptação à dieta e seis dias para mensuração do consumo e da digestibilidade dos nutrientes.
As rações (Tabelas 1 e 2) foram formuladas de acordo com o NRC (1989), adotando-se a relação volumoso:concentrado de 60:40, na matéria seca, para conterem em média $16 \%$ de proteína bruta.

Os animais foram pesados no início e ao final de cada período experimental. A dieta total foi fornecida à vontade na forma de mistura completa, duas vezes ao dia, às 6 h30 e $13 \mathrm{~h} 30$, e as sobras foram recolhidas e pesadas todos os dias para determinação do consumo diário. A quantidade de dieta fornecida foi calculada de modo a permitir aproximadamente $10 \%$ de sobras, e a água também foi fornecida à vontade. Para determinação da digestibilidade dos nutrientes entre o $10 \underline{\mathrm{o}}$ e $16 \underline{\mathrm{o}}$ dia de cada período experimental, foram efetuadas coletas de fezes na ampola retal às $8 \mathrm{~h}$ e às $15 \mathrm{~h} 30$, em dias alternados. Neste período, também foram coletadas amostras dos alimentos fornecidos e das sobras. As amostras de fezes, alimentos e sobras foram armazenadas a $-15^{\circ} \mathrm{C}$. Ao fim dos períodos de coleta, as amostras foram pré-secas em estufa de ventilação forçada, a $55^{\circ} \mathrm{C}$ por 72 horas, trituradas em moinho tipo Willey em peneiras de $1 \mathrm{~mm}$ e homogeneizadas para confecção de amostras compostas por animal para cada período. Os fluxos de matéria seca fecal foram estimados utilizando-se o teor de FDN indigestível $\left(\mathrm{FDN}_{\mathrm{i}}\right)$ como indicador. As amostras de fezes, alimentos e sobras foram incubadas in situ em sacos de náilon, por 144 horas, segundo metodologia descrita por Cochran et al. (1986). O material remanescente da incubação foi submetido a extração com solução em detergente neutro e o resíduo foi considerado FDN $_{\mathrm{i}}$.

As determinações dos teores de matéria seca (MS), matéria mineral (MM), matéria orgânica $(\mathrm{MO})$, proteína bruta $(\mathrm{PB})$ e extrato etéreo $(\mathrm{EE})$ foram realizadas conforme os procedimentos padrões descritos em AOAC (1990); e as de fibra em detergente neutro (FDN) e fibra em detergente ácido (FDA), conforme proposto por Van Soest et al. (1991). Os teores de carboidratos totais (CT), de carboidratos não-fibrosos, assim como os consumos de nutrientes digestíveis totais (NDT), foram obtidos conforme recomendações de Sniffen et al. (1992).

Para mensuração do comportamento ingestivo, os animais foram submetidos à observação visual no final de cada período experimental, durante dois dias consecutivos. No primeiro dia de observação, os animais foram avaliados durante três períodos contínuos de duas horas (8 às $10 \mathrm{~h}$; 14 às 16 h e 18 às 20 h) para coleta dos dados e estimativa do número de mastigações merícicas por bolo ruminal e do tempo despendido de mastigação merícica por bolo ruminal, utilizando-se cronômetro digital. No segundo 
Tabela 1 - Composição do concentrado utilizado com o feno com partículas de 5, 7,10 $\mathrm{mm}$ e inteiro

\begin{tabular}{lc}
\hline Ingrediente $(\%$ MS $)$ & Proporção $(\%)$ \\
\hline Fubá de milho & 60,00 \\
Farelo de trigo & 16,00 \\
Farelo de soja $^{\text {Suplemento mineral }}{ }^{1}$ & 20,00 \\
\hline
\end{tabular}

${ }^{1} 0,26 \%$ de fosfato bicálcico, $0,62 \%$ de cloreto de sódio, $0,12 \mathrm{~g} / 100 \mathrm{~kg}$ de sulfato de cobalto, 7,40 g/100 kg de sulfato de cobre, $0,24 \mathrm{~g} / 100 \mathrm{~kg}$ de iodato de potássio, $31,00 \mathrm{~g} / 100 \mathrm{~kg}$ de sulfato de zinco. con sumo de matéria seca. No entanto, o conteúdo de fibra da dieta poderia ter reflexos sobre o tempo médio de retenção da digesta e, como conseqüência, influenciar os consumos, porém isto não foi observado neste estudo. Esses resultados são semelhantes aos observados por Mooney \& Allen (1997) em estudos com silagem de milho com diversos tamanhos de partícula, aos de Grant et al. (1990) ao avaliar o consumo de feno de diferentes tamanhos de

Tabela 2 - Composição dos alimentos e do concentrado utilizados nas dietas experimentais, em porcentagem da matéria seca

\begin{tabular}{|c|c|c|c|c|c|c|}
\hline & Feno de capim-tifton 85 & Fubá de milho & Farelo de trigo & Farelo de soja & Concentrado & Dieta \\
\hline Matéria seca & 91,76 & 87,93 & 87,91 & 88,56 & 88,85 & 90,60 \\
\hline Matéria orgânica & 91,59 & 98,35 & 92,93 & 93,06 & 94,67 & 92,82 \\
\hline Proteína bruta & 14,36 & 9,82 & 16,79 & 45,68 & 17,27 & 15,53 \\
\hline Extrato etéreo & 1,96 & 4,15 & 3,56 & 1,63 & 3,93 & 2,75 \\
\hline Matéria mineral & 8,36 & 1,65 & 7,07 & 6,26 & 5,54 & 7,24 \\
\hline Carboidratos totais & 75,32 & 84,38 & 72,58 & 55,53 & 73,26 & 74,49 \\
\hline Fibra em detergente neutro & 79,18 & 12,00 & 49,48 & 14,81 & 17,18 & 54,38 \\
\hline Carboidratos não-fibrosos & 3,86 & 72,38 & 28,10 & 40,72 & 56,08 & 20,11 \\
\hline Fibra em detergente ácido & 40,02 & 6,00 & 13,73 & 9,56 & 6,29 & 26,53 \\
\hline
\end{tabular}

dia, o comportamento ingestivo de cada novilho foi determinado visualmente, a intervalos de cinco minutos, durante 24 horas, para determinação do tempo despendido em alimentação, ruminação e ócio (Johnson \& Combs, 1991). Na observação noturna dos animais, o ambiente foi mantido com iluminação artificial. As variáveis referentes ao comportamento ingestivo foram: tempo de alimentação (TAL, h/dia), tempo de ruminação (TRU, h/dia), tempo de mastigação total (TMT, h/dia) e número de bolos ruminais (NBR, No/dia). O tempo de mastigação total foi obtido a partir da seguinte relação: TMT $=\mathrm{TAL}+\mathrm{TRU}$, enquanto o $\mathrm{NBR}=\mathrm{TRU} / \mathrm{M}_{\mathrm{tb}}$, em que TRU/M $\mathrm{M}_{\mathrm{tb}}$ é o tempo de mastigação merícica por bolo ruminal (Polli et al., 1996).

As variáveis foram submetidas à análise de variância e as médias foram comparadas pelo teste de Tukey, a 1 e 5\% de probabilidade, utilizando-se o programa SAEG - Sistema de Análises Estatísticas e Genéticas (UFV, 1997).

\section{Resultados e Discussão}

Os consumos de matéria seca, fibra em detergente neutro, matéria orgânica, proteína bruta, extrato etéreo, carboidratos totais e carboidratos não-fibrosos não foram influenciados $(\mathrm{P}>0,05)$ pelos perfis granulométricos das dietas experimentais (Tabela 3 ) em nenhuma das formas de expressão, provavelmente porque as dietas experimentais eram isonutricionais .Assim, os níveis de energia e de FDN não poderiam realmente ter influenciado o partícula em rações para vacas leiteiras no início da lactação e aos obtidos por Bezerra et al. (2002), que também verificaram o efeito do perfil granulométrico de dietas sobre o desempenho de vacas em lactação.

Os consumos médios de matéria seca relativos ao peso vivo dos animais variaram de 2,06 a $2,33 \%$ e permaneceram na faixa considerada normal para essa categoria animal, nas condições fisiológicas e de peso em que se encontram, segundo os padrões de animais em crescimento (Holden et al., 1988; NRC, 1989; AFRC, 1993).

O consumo médio de FDN em \% do PV foi de 1,26\%, valor próximo ao recomendado pelo NRC (1989) para gado leiteiro, que sugere ingestão ótima de FDN, 1,2 ( $\pm 0,1) \%$ PV. Segundo Van Soest (1994), se a parede celular é limitante da ingestão, ela tem máximo de ingestão constante. Contudo, neste estudo, o nível de FDN na dieta não foi limitante nocontrole da ingestão voluntária. Como a relação volumoso:concentrado foi a mesma para todas as dietas (60:40) e não foi verificada influência do perfil granulométrico, pode-se inferir que em todas as dietas o controle da ingestão foi realizado pela demanda energética do animal, de acordo com as considerações realizadas por Conrad et al. (1964) e Van Soest (1994), os quais relataram que, em dietas com digestibilidade superior a $66 \%$, o consumo de matéria seca é controlado por fatores fisiológicos.

A digestibilidade da matéria seca (Tabela 4) diferiu $(\mathrm{P}<0,05)$ entre as dietas comtamanhos de partícula de 7 e $10 \mathrm{~mm}(67,31$ e $54,95 \%$, respectivamente). No entanto, as 
Tabela 3 - Consumos de nutrientes das dietas com feno capim-tifton de diversos tamanhos de partícula

\begin{tabular}{|c|c|c|c|c|c|}
\hline \multirow[t]{2}{*}{ Item } & \multicolumn{4}{|c|}{ Tamanho de partícula } & \multirow[b]{2}{*}{$\mathrm{CV}(\%)$} \\
\hline & $5 \mathrm{~mm}$ & $7 \mathrm{~mm}$ & $10 \mathrm{~mm}$ & Inteiro & \\
\hline Matéria seca (kg/dia) & 8,43 & 8,12 & 8,51 & 8,89 & 11,36 \\
\hline Matéria seca (\% PV) & 2,11 & 2,06 & 2,15 & 2,33 & 14,5 \\
\hline Matéria seca $\left(\mathrm{g} / \mathrm{kg}^{0,75}\right)$ & 94,32 & 91,65 & 95,68 & 102,65 & 14,02 \\
\hline Fibra em detergente neutro (kg/dia) & 5,11 & 4,57 & 4,91 & 5,26 & 14,91 \\
\hline Fibra em detergente neutro (\%PV) & 1,28 & 1,16 & 1,24 & 1,37 & 17,85 \\
\hline Fibra em detergente neutro $\left(\mathrm{g} / \mathrm{kg}^{0,75}\right)$ & 57,04 & 51,54 & 55,21 & 60,6 & 17,1 \\
\hline Matéria orgânica (kg/dia) & 7,82 & 7,54 & 7,89 & 8,23 & 11,21 \\
\hline Proteína bruta $(\mathrm{kg} / \mathrm{dia})$ & 1,31 & 1,27 & 1,31 & 1,37 & 10,61 \\
\hline Extrato etéreo (kg/dia) & 0,24 & 0,23 & 0,24 & 0,24 & 10,18 \\
\hline Caroboidratos totais $(\mathrm{kg} / \mathrm{dia})$ & 6,17 & 5,95 & 6,23 & 6,58 & 11,79 \\
\hline Carboidratos não-fibrosos (kg/dia) & 1,54 & 1,66 & 0,57 & 1,72 & 14,2 \\
\hline Nutrientes digestíveis totais $(\mathrm{kg} / \mathrm{dia})$ & 5,25 & 5,32 & 4,54 & 5,66 & 15,2 \\
\hline
\end{tabular}

dietas foram semelhantes àquelas com tamanhos de partícula de $5 \mathrm{~mm}$ ecom fenointeiro, que apresentaram valores intermediários, com média de 63,62\%.

O mesmo comportamento foi observado para a digestibilidade da matéria orgânica, que foi menor para a dieta com partículas de $10 \mathrm{~mm}(57,36 \%)$ em relação à dieta com perfil granulométrico de $7 \mathrm{~mm}$. Foi registrado valor médio de $66,68 \%$ para as dietas com tamanhos de partículas de $5,7 \mathrm{~mm}$ e feno inteiro.

Não foram registradas diferenças $(P>0,05)$ na digestibilidade da PB (Tabela 4) entre as dietas com tamanhos de partículas de 5, $7 \mathrm{~mm}$ ecom fenointeiro (valor médio de $69,39 \%$ ). A dieta com partículas de $10 \mathrm{~mm}$, no entanto, apresentou a menor digestibilidade $(58,15 \%)$.

Considerando os menores valores observados para a dieta com tamanho de partícula $10 \mathrm{~mm}$ para os coeficientes de digestibilidade da matéria seca e matéria orgânica, em comparação ao tamanho de partícula com $7 \mathrm{~mm}$, e para a digestibilidade da $\mathrm{PB}$, em relação aos demais tamanhos de partícula, as reduções dos coeficientes não foram suficientes para promover alterações no consumo destes componentes da dieta, considerando a estreita relação existente entre consumo e digestibilidade.

As digestibilidades de extrato etéreo, carboidratos totais, fibra em detergente neutro e fibra em detergente ácido não diferiram entre as dietas experimentais. Esses resultados podem ser explicados pelos processos mastigatórios e de ruminação, que podem ter promovido quebra nas barreiras estruturais do alimento resistente à digestão (Beauchemin et al., 1994), permitindo acesso bacteriano ao substrato de forma similar (Buxton \& Redfearn, 1997) e, dessa forma, propiciado maior área de superfície de contato, adesão e formação de biofilme.

As digestibilidades dos carboidratos não-fibrosos diferiram $(\mathrm{P}<0,05)$ para as dietas experimentais constituídas de $10 \mathrm{~mm}$ e o feno inteiro (76,64 e 87,19\%, respectivamente), no entanto, esses valores foram similares aos das dietas com partículas de 5 e $7 \mathrm{~mm}$, as quais apresentaram valor médio de 83,33\%. Segundo Valadares Filho et al. (1987), carboidratos não-fibrosos apresentam coeficiente de digestibilidade aparente total elevado, às vezes acima de $90 \%$, enquanto, para carboidratos estruturais, a digestibilidade aparente é próxima de $50 \%$ considerando, evidentemente, outros fatores inerentes, como tipo de forrageira, estádio vegetativo, entre outros. Van Soest (1994) e Mertens (1996) ressaltaram ainda que os carboidratos fibrosos, presentes em elevada concentração no feno de capim-tifton, apresentam disponibilidade lenta e incompleta e são, portanto, a principal fonte de variação na digestibilidade dos nutrientes.

A soma dos períodos 1 e 2 , referentes ao período das 6 às $12 \mathrm{~h}$ e das 12 às $18 \mathrm{~h}$, correspondeu ao maior tempo despendido para consumo (83,92\% do consumo total), logo, o consumo concentrou-se durante o dia (Figura 1). A ingestão de matéria seca também pode ter sido estimulada pelo fornecimento do alimento aos novilhos nestes períodos (6h30 e às 13h30; Dado \& Allen, 1995).

De acordo com Forbes (1995), como os bovinos são animais de hábito diurno, a atividade de alimentação é mais freqüente e ocupa o animal por mais tempo durante o dia que à noite, contudo esse comportamento pode variar em situações de altas temperaturas, o que não ocorreu neste estudo.

A ruminação ocorreu principalmente durante a noite, horário em que comumente a temperatura do ar é mais amena. A ruminação ocorreu, em grande parte, entre os períodos 3 e 4, ou seja, das 18 às 00 h e de 00 h às 6 h, respectivamente. O padrão diário da atividade de ruminação apresentou valores elevados 10 horas após o fornecimento da alimentação (período 3), mantendo-se em plena atividade 
Tabela 4 - Digestibilidade total de nutrientes, em \%, de dietas com feno de capim-tifton de diversos tamanhos de partícula

\begin{tabular}{lccccc}
\hline Item & \multicolumn{4}{c}{ Tamanho de partícula } \\
\cline { 2 - 5 } & $5 \mathrm{~mm}$ & $7 \mathrm{~mm}$ & $10 \mathrm{~mm}$ & Inteiro & CV $(\%)$ \\
\hline Matéria seca & $63,68 \mathrm{ab}$ & $67,31 \mathrm{a}$ & $54,95 \mathrm{~b}$ & $63,56 \mathrm{ab}$ & 6,05 \\
Matéria orgânica & $65,20 \mathrm{ab}$ & $68,88 \mathrm{a}$ & $57,36 \mathrm{~b}$ & $65,97 \mathrm{ab}$ & 5,99 \\
Proteína bruta & $68,16 \mathrm{a}$ & $72,95 \mathrm{a}$ & $58,15 \mathrm{~b}$ & $67,06 \mathrm{a}$ & 4,65 \\
Extrato etéreo & 65,04 & 73,42 & 65,61 & 70,32 & 12,88 \\
Carboidratos totais & 64,05 & 67,33 & 56,13 & 66,90 & 59,35 \\
Fibra em detergente neutro & 61,99 & 60,50 & 52,33 & 5,65 \\
Fibra em detergente neutro & 53,79 & 65,39 & 60,45 & 58,25 & 8,5 \\
Carboidratos não-fibrosos & $81,78 \mathrm{ab}$ & $84,89 \mathrm{ab}$ & $76,64 \mathrm{~b}$ & $87,19 \mathrm{a}$ & 4,27 \\
\hline
\end{tabular}

Médias seguidas de letras distintas diferem $(\mathrm{P}<0,05)$ pelo teste Tukey.

durante 12 horas subseqüentes (período 4). Polli et al. (1996) relataram que a distribuição da atividade de ruminação é bastante influenciada pela alimentação, uma vez que a ruminação ocorre logo após os períodos de alimentação, quando o animal está mais tranqüilo.

O tempo de alimentação, expresso em hora/dia, diferiu $(\mathrm{P}<0,05)$ quando os animais foram submetidos às dietas contendo feno de capim-tifton 85 inteiro e em partículas de $5 \mathrm{~mm}$, observando-se maior valor (6,85 horas) para animais recebendo feno de capim-tifton inteiro (Tabela 5). O tempo de alimentação dos animais que receberam as dietas com partículas de 7, $10 \mathrm{~mm}$ e com feno inteiro não diferiu $(\mathrm{P}>0,05)$. Beauchemin et al. (2003) atribuíram a ausência de efeito do perfil granulométrico de partículas em dietas à base de feno e silagem de alfafa para vacas Holandesas à redução do consumo com a utilização de maiores tamanhos de partícula, isso, porém, não foi verificado neste estudo.

O tempo de ruminação (TRU), expressos em horas/dia, foi maior $(\mathrm{P}<0,05)$ quando os animais foram submetidos à dieta com tamanho de partícula de $7 \mathrm{~mm}$ (8,81 horas/dia) em relação à dieta constituída de feno inteiro (7,38 horas/dia), mas não diferiu das dietas com 5 e $10 \mathrm{~mm}$ de tamanho de partícula $(\mathrm{P}>0,05)$. O aumento no tempo de ruminação na dieta com tamanho de partícula de $7 \mathrm{~mm}$ não apresentou reflexo sobre os coeficientes de digestibilidade da matéria seca da dieta, tendo em vista a semelhança entre as digestibilidades das dietas com tamanhos de partículas de $7 \mathrm{~mm}$ e feno inteiro. Beauchemin et al. (2003) verificaram resposta similar em pesquisa com vacas Holandesas recebendo dietas com diferentes proporções de feno de alfafa e silagem de alfafa, cujos tamanhos de partículas foram, respectivamente, de 4 e $10 \mathrm{~mm}$.

O tempo de mastigação total (TMT) dos animais submetidos às dietas com partículas de 7, $10 \mathrm{~mm}$ e com feno inteiro não diferiram $(\mathrm{P}>0,05)$ entre si, mas foram superiores ao obtido com a dieta com tamanho de partícula de $5 \mathrm{~mm}$. Este resultado está relacionado ao menor tempo de alimentação despendido com o tamanho de partícula de $5 \mathrm{~mm}$, o
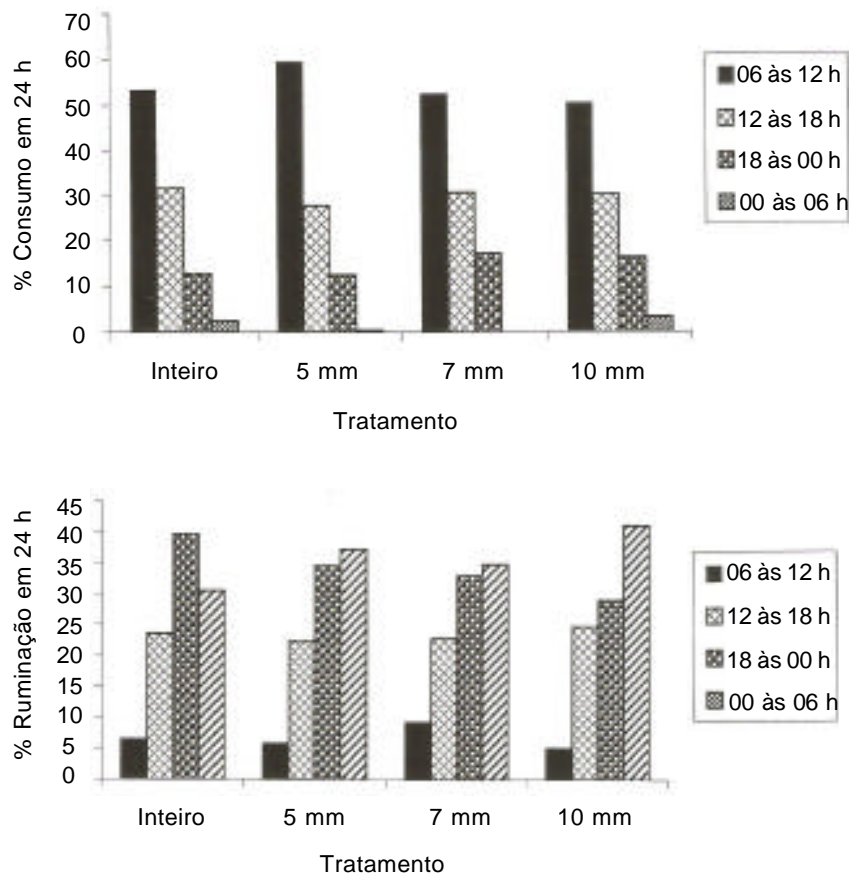

Figura 1 - Consumo e ruminação em quatro períodos (1, 2, 3 e 4), durante 24 horas, de dietas com feno de capim-tifton 85 inteiro e com tamanhos de partículas de 5, 7 e $10 \mathrm{~mm}$.

qual, mesmo apresentando tempo de ruminação semelhante aos demais tamanhos de partícula avaliados, não possibilitou que o tamanho de partícula apresentasse tempo de mastigação equivalente ao das demais dietas experimentais. O número de bolos ruminais (NBR) ingeridos por dia não foi influenciado $(\mathrm{P}>0,05)$ pelo perfil granulométrico das dietas e apresentou valor médio de 632,88.

A manutenção do consumo e a ausência de efeito dos tamanhos de partícula sobre a digestibilidade comprovaram que o comportamento ingestivo foi eficiente na liberaçãode nutrientes solúveis para fermentação ruminal, na exposição da fração interna do alimento à colonização pelos microrganismos e na hidratação dos componentes da dieta durante a insalivação. 
Tabela 5 - Tempos de alimentação, ruminação e mastigação total e número de bolos ruminais em bovinos alimentados com feno de capimtifton com diversos tamanhos de partícula

\begin{tabular}{|c|c|c|c|c|c|}
\hline \multirow[t]{2}{*}{ Item } & \multicolumn{4}{|c|}{ Tamanho de partícula } & \multirow[b]{2}{*}{$\mathrm{CV}(\%)$} \\
\hline & $5 \mathrm{~mm}$ & $7 \mathrm{~mm}$ & $10 \mathrm{~mm}$ & Inteiro & \\
\hline Tempo de alimentação (horas/dia) & $5,42 b$ & $5,81 \mathrm{ab}$ & $6,29 \mathrm{ab}$ & $6,85 \mathrm{a}$ & 8,47 \\
\hline Tempo de ruminação (horas/dia) & $7,58 \mathrm{ab}$ & $8,81 \mathrm{a}$ & $7,96 \mathrm{ab}$ & $7,38 b$ & 7,17 \\
\hline Tempo total de mastigação (horas/dia) & $13,00 \mathrm{~b}$ & $14,63 \mathrm{a}$ & $14,25 \mathrm{a}$ & $14,23 \mathrm{a}$ & 3,14 \\
\hline Número de bolos ruminais (№/dia) & 595,42 & 709,95 & 623,46 & 602,67 & 12,34 \\
\hline
\end{tabular}

\section{Conclusões}

O tamanho de partícula do feno de capim-tifton 85 utilizado em dietas completas não influencia o consumo, a digestibilidade dos nutrientes e o comportamento ingestivo de novilhos da raça Holandesa.

\section{Literatura Citada}

AGRICULTURAL AND FOOD RESEARCH COUNCIL - AFRC. Energy and protein requirements of ruminants. Wallingford: CAB International, 1993. 159p.

ASSOCIATION OF OFFICIAL ANALYTICAL CHEMISTS - AOAC. Official methods of analysis.15. ed. Virginia: 1990. v.1, $1117 \mathrm{p}$.

BEAUCHEMIN, K.A.; McALLISTER, T.A.; DONG, Y. et al. Effects of mastication on digestion of whole cereal grains by cattle. Journal of Animal Science, v.72, n.2, p.236-246, 1994

BEAUCHEMIN, K.A.; YANG, W.Z.; RODE, L.M. et al. Effects of particle size of alfafa-based dairy cow diets on chewing activity, ruminal fermentation and milk production. Journal of Dairy Science, v.86, n.2, p.630-643, 2003.

BEZERRA, E.S.; QUEIROZ, A.C.; MALDONADO, F. et al.Efeito do perfil granulométrico das partículas dietéticas sobre parâmetros de desempenho de vacas leiteiras em lactação. Revista Brasileira de Zootecnia, v.31, n.3, p.1511-1520, 2002 (supl.).

BUXTON, D.R.; REDFEARN, D.D. Plant limitations to fiber digestion and utilization. Journal of Nutrition, v.127, n.5, p. 814-818, 1997 (supl.).

COCHRAN, R.C.; ADAMS, D.C.; WALLACE, J.D. et al. Predicting digestibility diets with internal markers: evaluation of four potential markers. Journal of Animal Science, v.63, p.1476$1483,1986$.

CONRAD, H.R.; PRATT, A.D.; HIBBS, J.W. Regulation of feed intake in dairy cows. I. Change in importance of physical and physiological factors with increasing digestibility. Journal of Dairy Science, v.47, n.1, p.54-62, 1964.

DADO, R.G.; ALLEN, M.S. Intake limitation, feeding behavior and rumen function of cows challenger with rumen filt from dietary fiber or inert bulk. Journal of Dairy Science, v.78, n.1, p.118133, 1995.

FORBES, J.M. Voluntary food intake and diet selection in farm animals. 1.ed. Leeds: CAB International, 1995. 532p.

FORBES, J.M. Integration of regulatory signals controlling forage intake in ruminants. Journal of Animal Science, v.74, n.12, p.3029-3035, 1996.

GRANT, R.J.; COLENBRANDER, V.F.; MERTENS, D.R. Milk fat depression in dairy cows: role of particle size of alfafa hay. Journal of Dairy Science, v.73, n.12, p.1823, 1990.
HODEN, A.; COULON, J.B.; FAVERDIN, P. Alimentação de vacas leiteiras. In: JARRIGE, R. (Ed.) Alimentação de bovinos, ovinos e caprinos. Paris: INRA, 1988. p.132-154.

JOHNSON, T.R.; COMBS, D.K. Effects of prepartum diet, inert rúmen bulk and dietary polyethylene glycol on dry matter intake of lactating dairy cows. Journal of Dairy Science, v.74, n.3, p.933-944, 1991.

MERTENS, D.R. Análise da fibra e sua utilização na avaliação e formulação de rações. In: REUNIÃO ANUAL DA SOCIEDADE BRASILEIRA DE ZOOTECNIA, 29., 1992, Lavras. Anais... Lavras: Sociedade Brasileira de Zootecnia, 1992. p.188-219.

MERTENS, D.R. Regulation of forage intake. In: FAHEY JR., G.C. (Ed.). Forage quality evaluation and utilization. Madison: American Society of Agronomy; Crop Science Society of America; Soil Science of America, 1994. p.450-493.

MERTENS, D.R. Using fiber and carbohydrate analyses to formulate dairy rations. In: INFORMATIONAL CONFERENCE WITH DAIRY AND FORAGES INDUSTRIES, 1996, Wisconsin. Proceedings... Wisconsin: 1996. p.81-92.

MOONEY, C. S.; ALLEN, M. S. Physical effectiveness of the neutral detergent fiber of whole linted cottonseed relative to that of alfalfa silage at two lengths of cut. Journal of Dairy Science, v.80, n.9, p.2052-2061, 1997.

NATIONAL RESEARCH COUNCIL - NRC. Nutrient requirements of dairy cattle. 6.ed. Washington, D.C.: 1989. 157p.

POLLI, V.A.; RESTLE, J.; SENNA, D.B. et al. Aspectos relativos à ruminação de bovinos e bubalinos em regime de confinamento. Revista Brasileira de Zootecnia, v.25, n.5, p.987-993, 1996.

SILVA, J.F.C. Mecanismos reguladores de consumo. In: BERCHIELLI, T.T.; PIRES, A.V.; OLIVEIRA, S.G. (Eds.) Nutrição de ruminantes. Jaboticabal: Funep, 2006. p.57-78.

SNIFFEN, C.J.; O'CONNOR, D.J.; Van SOEST, P.J. et al. A net carbohydrate and protein system for evaluating cattle diets: carbohydrate and protein availability. Journal of Animal Science, v.70, n.12, p.3562-3577, 1992.

UNIVERSIDADE FEDERAL DE VIÇOSA - UFV. Sistema de análises estatísticas e genéticas - SAEG . Viçosa, MG: UFV, 1997. (Apostila).

VALADARES FILHO, S.C.; SILVA, J.F.C.; LEÃO, M.I. Estudo comparativo da digestão de matéria seca e carboidratos em bovinos e bubalinos alimentados com diferentes rações. Revista Brasileira de Zootecnia, v.16, n.2, p.120-130, 1987.

Van SOEST, P.J. Nutritional ecology of the ruminant. 2.ed. Ithaca: Cornell University Press, 1994. 476p.

Van SOEST, P.J.; ROBERTSON, J.B.; LEWIS, B.A. Methods for dietary fiber, neutral detergent fiber, and nonstarch polysaccharides in relation to animal nutrition. Journal of Dairy Science, v.74, n.10, p.3583-3597, 1991.

YANG, W.Z.; BEAUCHEMIN, K.A. Effects of physically effective fiber on chewing activity and ruminal $\mathrm{pH}$ of dairy cows fed diets based on barley silage. Journal of Dairy Science, v.89, n. 1, p. $217-228,2006$ 